\title{
Geothermal heating, diapycnal mixing and the abyssal circulation
}

\author{
J. Emile-Geay ${ }^{1}$ and G. Madec ${ }^{2, *}$ \\ ${ }^{1}$ Department of Earth Sciences, University of Southern California, Los Angeles, USA \\ ${ }^{2}$ Laboratoire d'Océanographie et du Climat: Expérimentations et Approches Numériques, Unité Mixte de Recherche 7159 \\ CNRS/IRD/UPMC/MNHN, Institut Pierre Simon Laplace, Paris, France \\ *also at: National Oceanography Centre, Southampton, UK
}

Received: 21 May 2008 - Published in Ocean Sci. Discuss.: 7 July 2008

Revised: 28 April 2009 - Accepted: 29 May 2009 - Published: 19 June 2009

\begin{abstract}
The dynamical role of geothermal heating in abyssal circulation is reconsidered using three independent arguments. First, we show that a uniform geothermal heat flux close to the observed average $\left(86.4 \mathrm{~mW} \mathrm{~m}^{-2}\right)$ supplies as much heat to near-bottom water as a diapycnal mixing rate of $\sim 10^{-4} \mathrm{~m}^{2} \mathrm{~s}^{-1}$ - the canonical value thought to be responsible for the magnitude of the present-day abyssal circulation. This parity raises the possibility that geothermal heating could have a dynamical impact of the same order. Second, we estimate the magnitude of geothermally-induced circulation with the density-binning method (Walin, 1982), applied to the observed thermohaline structure of Levitus (1998). The method also allows to investigate the effect of realistic spatial variations of the flux obtained from heatflow measurements and classical theories of lithospheric cooling. It is found that a uniform heatflow forces a transformation of $\sim 6 \mathrm{~Sv}$ at $\sigma_{4}=45.90$, which is of the same order as current best estimates of AABW circulation. This transformation can be thought of as the geothermal circulation in the absence of mixing and is very similar for a realistic heatflow, albeit shifted towards slightly lighter density classes. Third, we use a general ocean circulation model in global configuration to perform three sets of experiments: (1) a thermally homogenous abyssal ocean with and without uniform geothermal heating; (2) a more stratified abyssal ocean subject to (i) no geothermal heating, (ii) a constant heat flux of $86.4 \mathrm{~mW} \mathrm{~m}^{-2}$, (iii) a realistic, spatially varying heat flux of identical global average; (3) experiments (i) and (iii) with enhanced vertical mixing at depth. Geothermal heating and diapycnal mixing are found to interact non-linearly through the density field, with geothermal heating eroding the deep stratification supporting a downward diffusive flux, while diapycnal mixing acts to map near-surface temperature gradients
\end{abstract}

Correspondence to: J. Emile-Geay (julieneg@usc.edu) onto the bottom, thereby altering the density structure that supports a geothermal circulation. For strong vertical mixing rates, geothermal heating enhances the AABW cell by about $15 \%(2.5 \mathrm{~Sv})$ and heats up the last $2000 \mathrm{~m}$ by $\sim 0.15^{\circ} \mathrm{C}$, reaching a maximum of by $0.3^{\circ} \mathrm{C}$ in the deep North Pacific. Prescribing a realistic spatial distribution of the heat flux acts to enhance this temperature rise at mid-depth and reduce it at great depth, producing a more modest increase in overturning than in the uniform case. In all cases, however, poleward heat transport increases by $\sim 10 \%$ in the Southern Ocean. The three approaches converge to the conclusion that geothermal heating is an important actor of abyssal dynamics, and should no longer be neglected in oceanographic studies.

\section{Introduction}

The abyssal circulation is generally pictured as closing the heat budget between downward diffusion from the warm surface layers and a widespread upwelling of cold, deep waters, balancing highly localized deep water sources (Warren, 1981). Stommel and Arons (1960) first explored the consequences of this statement by assuming a uniform upwelling rate at the base of the main thermocline, and showing that this would govern a Sverdrup-like circulation in the interior, from which they inferred the necessary existence of deep westernboundary currents accomplishing interbasin mass transport. The existence and directions of these currents had been suggested by laboratory experiments Stommel et al. (1958) and was later confirmed by in situ measurements (see Arhan et al. (1998); Whitworth et al. (1999) and references therein). In this framework, the driving force of the abyssal circulation is the downward diffusion of heat, which controls the global upwelling rate, thereby setting the magnitude of the meridional overturning circulation (MOC). This classical view still prevails in spite of much work having been done to understand the effect of non-uniform mixing rates and wind-forced

Published by Copernicus Publications on behalf of the European Geosciences Union. 
upwelling in the Southern Ocean (e.g. Webb and Suginohara, 2001; Toggweiler and Samuels, 1995, 1998; Visbeck, 2007).

Of course, the deep ocean is subjected to another heat source: the geothermal flux due to lithospheric cooling. Yet the latter is usually neglected in oceanographic studies, primarily because it amounts to less than $2 \%$ of surface heat fluxes (Huang, 1999) - a total power of $0.03 \mathrm{PW}$ and a mean flux of $\sim 88 \mathrm{~mW} \mathrm{~m}^{-2}$ (Stein and Stein, 1992), while surface fluxes are on around 30 to $250 \mathrm{~W} \mathrm{~m}^{-2}$, larger by three orders of magnitudes. Although it is clear that geothermal heat flux is weak compared to the surface ones, pointwise comparisons are misleading. First, geothermal heat flux is systematically positive whereas surface fluxes are of both signs, leading to important cancellations on a global scale. Second, the geothermal heat flow acts only on the densest water masses, which are only in contact with the atmosphere in very limited areas at high latitudes, where they are formed through heat and freshwater loss to the atmosphere and sea-ice. Those deep-water formation areas only represent a few thousandths of the global ocean surface, as opposed to a geothermal heat flux spanning the entire seafloor. It turns out that the ratio between the AABW outcropping area and the total seafloor area is about one to a thousand, therefore the surface integrals of the two fluxes scale comparably.

In the present study, we focus on the large-scale, conductive geothermal heat flux - ignoring the localized effect of hydrothermal vents - and ask how it affects the global abyssal circulation. A similar question was raised by Adcroft et al. (2001), using an ocean general circulation model (GCM) in global configuration to assess the effect of a uniform heatflow of $50 \mathrm{~mW} \mathrm{~m}^{-2}$ at the base of their model. They obtained a first order change in abyssal water properties (a warming of about 0.3 to $0.5^{\circ} \mathrm{C}$ ) and a fairly weak dynamical response (about $1.8 \mathrm{~Sv}$ in the Indo-Pacific). These original results were further clarified by Scott et al. (2001) in an idealized setting. Their essential finding is that the response to geothermal heating is largely advective: a deep circulation cell communicates the anomalous heat to the surface so that steady-state can be achieved. Moreover, they found this circulation to require the existence of a background ("StommelArons") circulation, and to be inversely proportional to the deep stratification. The goal of this article is to further clarify the interaction between geothermal and background circulations, in a more realistic setting. In so doing, we take into account the spatial variations of the heatflow.

The paper is structured as follows: in Sect. 2 we develop a realistic representation of geothermal heatflow derived from standard theories of lithospheric cooling. We then compare diapycnal mixing and geothermal heating and show that they are on equal footing near the bottom (Sect. 3). In Sect. 4 we estimate the magnitude of the geothermal circulation using the thermodynamic method of density-binning, and investigate the effect of the spatial structure of the flux. In Sect. 5 we report the results of 3 sets of experiments carried out with an ocean general circulation model in the presence of
(1) no geothermal heating, (2) uniform geothermal heating, (3) spatially variable geothermal heating. Discussion follows in Sect. 6.

\section{A global heatflow dataset for ocean studies}

To the best of our knowledge, such a dataset does not currently exist, as the measurement of conductive heatflow in the superficial sediments are too sparse. To fill in the blanks, Pollack et al. (1993) proposed to use the age of the bedrock, which is reasonably well known (Müller et al., 1997), as a proxy for heatflow ${ }^{1}$. Like Pollack et al. (1993), we used the Stein and Stein (1992) formula relating the heatflow (in $\mathrm{mW} \mathrm{m}{ }^{-2}$ ) to the age of the bedrock, $t$, in million years (Ma):

$$
Q_{\mathrm{geo}}= \begin{cases}510 t^{-1 / 2} & \text { if } t \leq 55 \mathrm{Ma} \\ 48+96 \exp (-0.027 t) & \text { if } t>55 \mathrm{Ma}\end{cases}
$$

The seafloor age was taken from the Müller et al. (1997) high-resolution global dataset $\left(0.1^{\circ} \times 0.1^{\circ}\right)$, containing very few regions of undetermined age. Their surface is quite large, though, especially East of Australia and Indonesia, where the flux was estimated by nearest-neighbor interpolation. This spatial representation is shown in Fig. 1. One clearly recognizes the ridge system, where oceanic lithosphere is formed at high temperature (about $1350^{\circ} \mathrm{C}$ ), before cooling down and thickening away from the ridge as plates diverge. Ridges therefore display a maximum heat flux, while the minimum is $\sim 50 \mathrm{~mW} \mathrm{~m}^{-2}$ on the deepest (and oldest) abyssal plains. Since Eq. (1) becomes singular for young ages, $Q_{\text {geo }}$ was bounded to $400 \mathrm{~mW} \mathrm{~m}^{-2}$, as $95 \%$ of measurements fall below this value. This yields a global mean of $86.4 \mathrm{~mW} \mathrm{~m}^{-2}$, compatible with observations (Pollack et al., 1993). One must however be cognizant of the uncertainties in this dataset: in addition to the uncertainties in the seafloor age estimates, coefficients in the formulae of Stein and Stein (1992) carry their own uncertainty by virtue of being indirectly obtained through least-square fits of theoretical predictions of global depth and heatflow to actual measurements, and they vary somewhat from basin to basin (the misfit being largest in the Indian Ocean, see Stein and Stein (1994)). A back-of-envelope calculation of error propagation shows these biases to dominate the total uncertainty in the dataset presented here. While a thorough examination of these errors is beyond the scope of this paper, we make the case that ours is likely to be conservative estimate of seafloor heat flow.

\footnotetext{
${ }^{1}$ We did not follow Huang (1999)'s suggestion to use the bathymetry as a proxy for the age of lithosphere, for this produced unrealistically large fluxes in regions where small-scale topographical structures are present (e.g. coral reefs, continental margins, hot spot tracks, ninety-west ridge): the latter are largely uncorrelated with the planetary-scale structures due to thermal lithospheric subsidence
} 


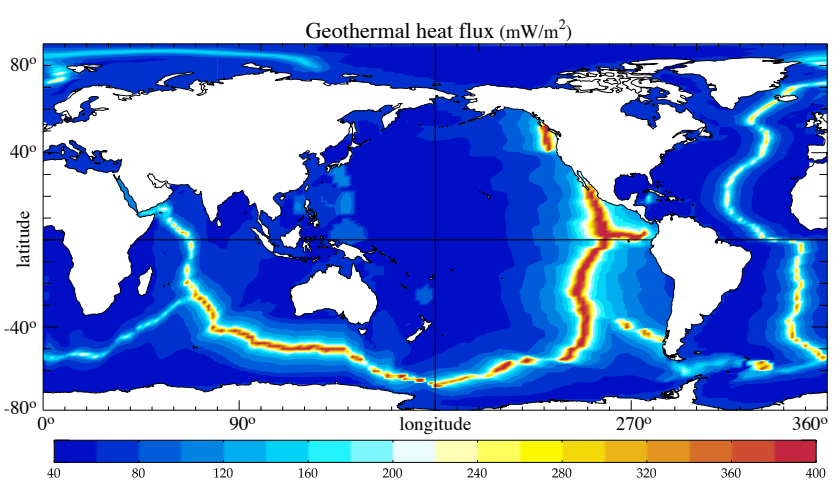

Fig. 1. Geothermal heat flux, as inferred from the age of the seafloor and the formulae of Stein and Stein (1992) (Eq. 1).

Firstly, the coefficient estimation was carried out on measurements that excluded high values $\left(>150 \mathrm{~mW} \mathrm{~m}^{-2}\right)$ on the grounds that they reflected hydrothermal processes (Stein and Stein, 1994). What matters for our present purpose is the heat released from the crust into the ocean, which such a procedure would underestimate. In addition, Hutnak and Fisher (2007) show that rapid sedimentation and conductive thermal rebound following the cessation of hydrothermal activity can jointly account for a downward bias in heatflow measurements of $\sim 5-30 \%$. More generally, Jaupart et al. (2007) argue that "heat flux measurements require sedimentary cover and hence are systematically biased towards anomalously low heat flux areas" (see also Harris and Chapman, 2004). Accordingly, the global heatflow estimate presented here should be viewed as a lower bound, to be refined in a future study.

\section{Geothermal vs diapycnal fluxes}

Let us consider the heat budget of a volume of seawater in contact with the seafloor, with unit horizontal surface and height $h$. The heat per unit mass is $C_{p} T$ and its conservation equation can be written:

$$
\partial_{t} T+\mathbf{u} \cdot \nabla T=\nabla \cdot(K \nabla T)+\frac{Q_{\mathrm{geo}}}{\rho_{\circ} C_{p}} \delta(z+H)
$$

where $T$ is the potential temperature, $K$ is the thermal diffusivity, $\rho_{\circ}$ a reference density (namely $1025 \mathrm{~kg} \mathrm{~m}^{-3}$ ), $Q_{\text {geo }}$ the geothermal heat flux (about $86.4 \mathrm{~mW} \mathrm{~m}^{-2}$ on a global average) and $C_{p}$ the heat capacity of seawater. The deltafunction means that the flux is only present at the bottom, $z=-H(x, y)$, and vanishes in the interior (for dimensional consistency, the $\delta$ function embodies the dimension of an in- verse length). Equivalently, it is the bottom boundary condition of the interior diffusive heat flux, i.e.:

$\left.\rho_{\circ} C_{p} K_{z} \partial_{z} T\right|_{z=-H}=Q_{\mathrm{geo}}(x, y)$

Geothermal heat flux must be compared to the relevant quantity for abyssal dynamics: the downward, turbulent heat flux, which is thought to control abyssal circulation. In usual turbulence closure theories, this flux is expressed as the product of the vertical thermal gradient by a vertical mixing coefficient $\left(K_{z}\right)$. The former can be estimated from the Levitus (1998) temperature data, knowing that their resolution at depth is of order $200 \mathrm{~m}$, up to $500 \mathrm{~m}$ below $3750 \mathrm{~m}$. The latter is very poorly known. As Munk and Wunsch (1998) pointed out, the deep ocean suffers a "dichotomy of diffusivities", since the value inferred by Munk (1966) to sustain abyssal stratification against global upwelling associated with $25 \mathrm{~Sv}$ of deep water formation is about $10^{-4} \mathrm{~m}^{2} \mathrm{~s}^{-1}$, which contrasts sharply with the $10^{-5} \mathrm{~m}^{2} \mathrm{~s}^{-1}$ given by microstructure (Gregg, 1989; Kunze and Sanford, 1996) and dye release measurements (Ledwell et al., 1998) away from regions of rough topography. One way to compare the upward geothermal flux and the downward diffusive flux is to consider a fixed diapycnal mixing coefficient of, say, $10^{-4} \mathrm{~m}^{2} \mathrm{~s}^{-1}$ and then compute an upper bound for the downward diffusive flux using the temperature data. This is done in Fig. 2: near the bottom, it is clear that even for such a strong mixing rate, a geothermal heating of $\mathrm{O}\left(100 \mathrm{~mW} \mathrm{~m}^{-2}\right)$ is still commensurate to turbulent mixing.

Another way to see this is to use the same temperature data to determine the vertical gradient, and to diagnose the value that $K_{z}$ would need to take for the diffusive heat flux to equal a geothermal heating of $86.4 \mathrm{~mW} \mathrm{~m}^{-2}$. Note that this is not a balance per se (since both fluxes bring heat into the abyss), but is a simple way of comparing their relative magnitudes. This "equivalent $K_{z}$ " is defined by the relation:

$\left|K_{\mathrm{eq}}\right|=\left|\frac{Q_{\mathrm{geo}}}{\rho_{\mathrm{o}} C_{p}}\right|\left|\frac{\partial T}{\partial z}\right|^{-1}$

which is plotted in Fig. 3 for $z=-4000 \mathrm{~m}$. It appears that this diagnosis requires, over much of the ocean, $K_{\text {eq }} \geq 10^{-4} \mathrm{~m}^{2} \mathrm{~s}^{-1}$ (this is especially true in the North Pacific, where deep stratification is very weak). In the Western Boundary regions of the southern Hemisphere, such as the Brazil basin, the superposition of the relatively warm North Atlantic Deep Water (NADW) over the cold Antarctic Bottom Water $(\mathrm{AABW})$ is responsible for a very strong vertical temperature gradient. As a result, even small mixing can produce a downward heat flux as strong as geothermal heating. We therefore expect geothermal heat flux to be dynamically important in the North Pacific, but insignificant in the Brazil basin. Averaging on the global scale, a geothermal heating of 


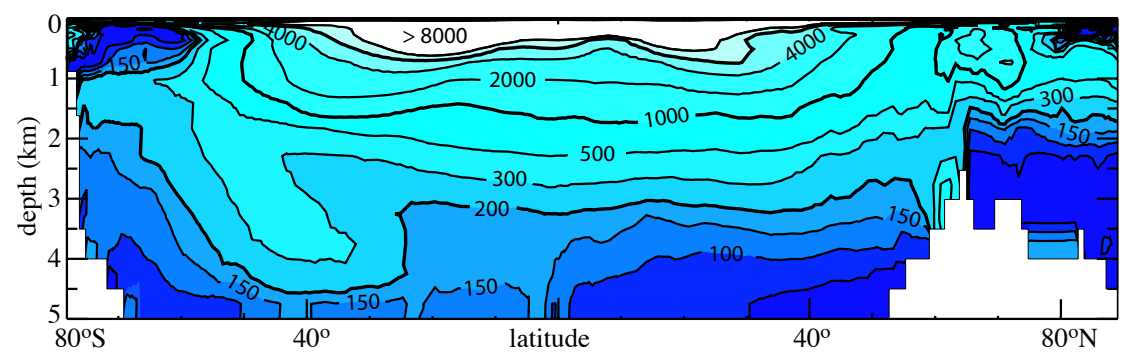

Fig. 2. Zonally-averaged downward diffusive heat flux $\left(K_{z} \frac{\partial T}{\partial z}\right)$ for a turbulent diffusivity of $10^{-4} \mathrm{~m}^{2} \mathrm{~s}^{-1}$. Units: $\mathrm{mW} \mathrm{m}-2$.

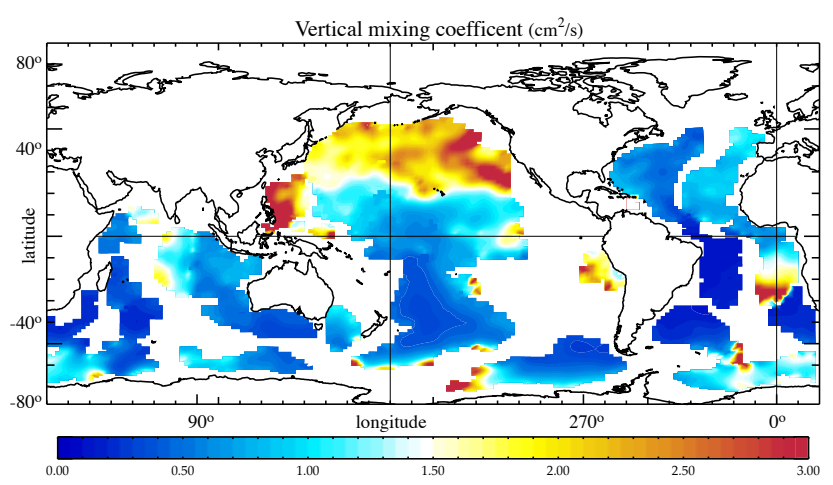

Fig. 3. $K_{\text {eq }}$ at $4000 \mathrm{~m}$ (see text for details). The quantity averages to $1.2 \times 10^{-4} \mathrm{~m}^{2} \mathrm{~s}^{-1}$.

$86.4 \mathrm{~mW} \mathrm{~m}-2$ is seen equivalent to a mean diapycnal mixing rate of $10^{-4} \mathrm{~m}^{2} \mathrm{~s}-1$ (the reason for the difference with the previous diagnostic is due to the non-commutability of the average and inverse operations). We are thus brought to the conclusion that, far from being negligible, geothermal heating is an essential term in the heat balance of the abyssal ocean.

Since the work of Stommel and Arons (1960) and the clear demonstration of Bryan (1987), it is thought that the intensity of abyssal circulation is chiefly controlled by the heat supplied to the deep ocean. While NADW is now understood to be a largely adiabatic circulation mainly driven by surface forcing and mixing in the Southern Ocean (Toggweiler and Samuels, 1995, 1998; Webb and Suginohara, 2001; Iudicone et al., 2008c,a), the circulation associated with AABW shows great sensitivity to vertical mixing parameterization in most ocean general circulation models (as will be seen again in Sect. 4). The equivalence between $Q_{\text {geo }}$ and $K_{z}$ means that one should expect them to generate a circulation of comparable magnitude, all other things being equal. In the next two sections, we estimate this circulation in two independent ways.

\section{Geothermal heating and diapycnal fluxes: the ther- modynamic method}

\subsection{The formation/consumption cycle of bottom water}

An apt metaphor for the thermohaline circulation is that of a cycle of formation, transformation and consumption of water masses. Bottom and deep waters are formed at high latitudes through buoyancy loss to the atmosphere. These physical properties are then "convectively churned" towards great depth (Send and Marshall, 1995), where they are further transformed by processes such as entrainment and sill mixing. Thus isolated from the surface - and remembering that the deep ocean is essentially aphotic below $100 \mathrm{~m}$ depth - the only process that can alter these water mass properties is diapycnal mixing, without which the ocean would fill up with cold, dense waters in a few thousand years (Munk, 1966). Hence, in steay-state, forming a water mass is only synonym of circulation if it is consumed. Diapycnal fluxes in the ocean interior, primarily associated with mixing, are then "the return limb of the ocean thermohaline circulation" (Toole et al., 1994), and control the intensity of the AABW circulation (Bryan, 1987). In the introduction of this paper, we have already mentioned a point of primary importance: that geothermal heat flux is systematically positive, thus supplying buoyancy to bottom water. Moreover, its action is precisely limited to bottom water (an endpoint of the T-S diagram), which means that geothermal heating tends to transform the densest water masses into warmer, lighter ones, much like air-sea fluxes transform surface waters. Indeed, a parcel of Antarctic Bottom Water (AABW) experiences a steady warming while heading North in the vicinity of the seafloor, in the same fashion as air-sea fluxes determine the thermal history of North Atlantic surface water while it ascends to high Northern latitudes (Walin, 1982; Speer and Tziperman, 1992; Large and Nurser, 2001; Marshall et al., 1998; Nurser et al., 1999; Iudicone et al., 2008b). To observe this analogy, one just needs to conceptually flip the ocean upside down, as done in Fig. 4. We can therefore assess the transformation due to geothermal heating following the pioneering concepts developed by Walin (1982) and followers. 


\subsection{The transformation framework}

We shall now consider the ocean in the isopycnal/diapycnal coordinates, which are less intuitive, but are more physically meaningful than the traditional horizontal/vertical coordinates. Geothermal heating is responsible for a buoyancy flux $\mathfrak{B}$ :

$\mathfrak{B}(x, y)=-\frac{\alpha_{\theta}}{C_{p}} Q_{\mathrm{geo}}(x, y)$

where $\alpha_{\theta}$ is the thermal expansion coefficient. On the time scales relative to ocean circulation, geothermal heating is assumed to be constant so that $Q_{\text {geo }}(x, y)$ is such as described in Sect. 1. It defines a two dimensional, stationary buoyancy flux, which can then be converted into a transformation per density class $F(\sigma)$ (more precisely $\sigma_{4}$, referenced at $4000 \mathrm{~m}$ ) using the same formulation as Speer et al. (2000):

$F(\sigma)=\iint_{\mathbb{A}} \mathfrak{B}(x, y) \delta\left(\sigma^{\prime}(x, y)-\sigma\right) \mathrm{d} x \mathrm{~d} y$

where $\mathbb{A}$ is the area of the seafloor. The delta function allows to sample the points of the seafloor where the density anomaly $\sigma^{\prime}(x, y)$ equals $\sigma$, so that we obtain the integral of the buoyancy flux over a portion of the seabed covered by density classes between, say, $\sigma$ and $\sigma+\Delta \sigma . \Delta \sigma$ is called the binning interval, $0.02 \mathrm{~kg} \mathrm{~m}^{-3}$ in our case. This probably overestimates the accuracy of our knowledge of the density field at depth, but allows for a numerically more stable solution. The set of possible values for $\sigma$ is [45.6, 46.2]. $F(\sigma)$ is called the "transformation" by geothermal heat flux, and its derivative with respect to $\sigma$ the "formation", denoted by $M$ (Speer and Tziperman, 1992; Nurser et al., 1999).

Define the net advective diapycnal flux $A(\sigma)$ and the diffusive diapycnal flux $D(\sigma)$ by their integral along the isopycnal surface intersecting the bottom (but not the surface; this requires the outcropping zone of $\mathrm{AABW}$ to be excluded from the domain):

$A(\sigma)=\int_{\mathbb{A}_{\sigma}} \mathbf{u} \cdot \mathbf{n} \mathrm{d} S$

where $\mathbf{n}$ is the unit normal vector to isopycnal $\sigma, \mathbf{u}$ is the velocity, and $\mathrm{d} S$ the surface element of the total area of the isopycnal, $\mathbb{A}_{\sigma}$. The diffusive flux across isopycnal $\sigma$ is:

$D(\sigma)=-\int_{\mathbb{A}_{\sigma}} \kappa \frac{\partial \sigma}{\partial n} \mathbf{n} \mathrm{d} S$

One can show (Walin, 1982; Speer et al., 2000; Iudicone et al., 2008b) that mass and density conservation then lead to the transformation equation:

$F(\sigma)-A(\sigma)-\frac{\partial D}{\partial \sigma}=0$

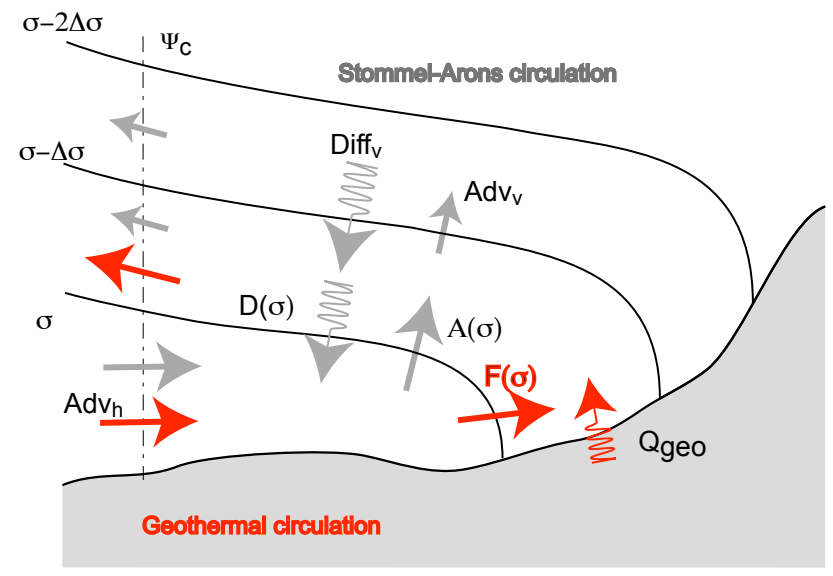

Fig. 4. Transformation of bottom water induced by geothemal heating. See text for details.

and the water mass formation equation:

$M(\sigma)=-\frac{\partial F}{\partial \sigma}+\frac{\partial^{2} D}{\partial \sigma^{2}}=\psi_{c}$ (in steady state)

where $\psi_{c}$ is the streamfunction at the edge of the domain.

These expressions describe the relationship between the transformation due to bottom buoyancy flux (geothermal), diapycnal advection and diapycnal mixing. The magnitude of $F$ for each density class gives the amount of crossisopycnal transport required to close the budget, "in the absence of mixing". With this tool in hand, we can now diagnose the tranformation due to geothermal heating in the ocean.

\subsection{Results: impact of a realistic heatflow}

In Fig. 5a we present the aforementioned transformation as a function of the density anomaly $\sigma_{4}$ (referenced at $4000 \mathrm{~m}$ ). The latter was computed using in situ Levitus (1998) potential temperature and salinity data, using the Jackett and McDougall (1995) equation of state. The chosen domain excludes the outcropping zones of the deepest isopycnals (i.e. the Nordic seas and the southernmost part of the Southern Ocean (poleward of $50^{\circ} \mathrm{S}$ ) so that the previous formulae do not need to explicitly include the effect of air-sea fluxes. The resolution at depth is quite problematic in these datasets, as the bottom boundary layer is not resolved. As a consequence, the quantity we compute is not the heat input over the seafloor area delineated by two isopycnals, but rather, the heat released into the bottom layer at some height above the isopycnal intersection with the seafloor.

Figure $5 \mathrm{~b}$ displays the area of the seafloor that is covered by each isopycnal layer (i.e. water masses whose density falls between $\sigma$ and $\sigma+\Delta \sigma)$. The curve is unimodal and peaks at the central density of AABW $\sigma=45.85$. Figure $5 \mathrm{c}$ shows the value of geothermal heat flux between the same isopycnals. 

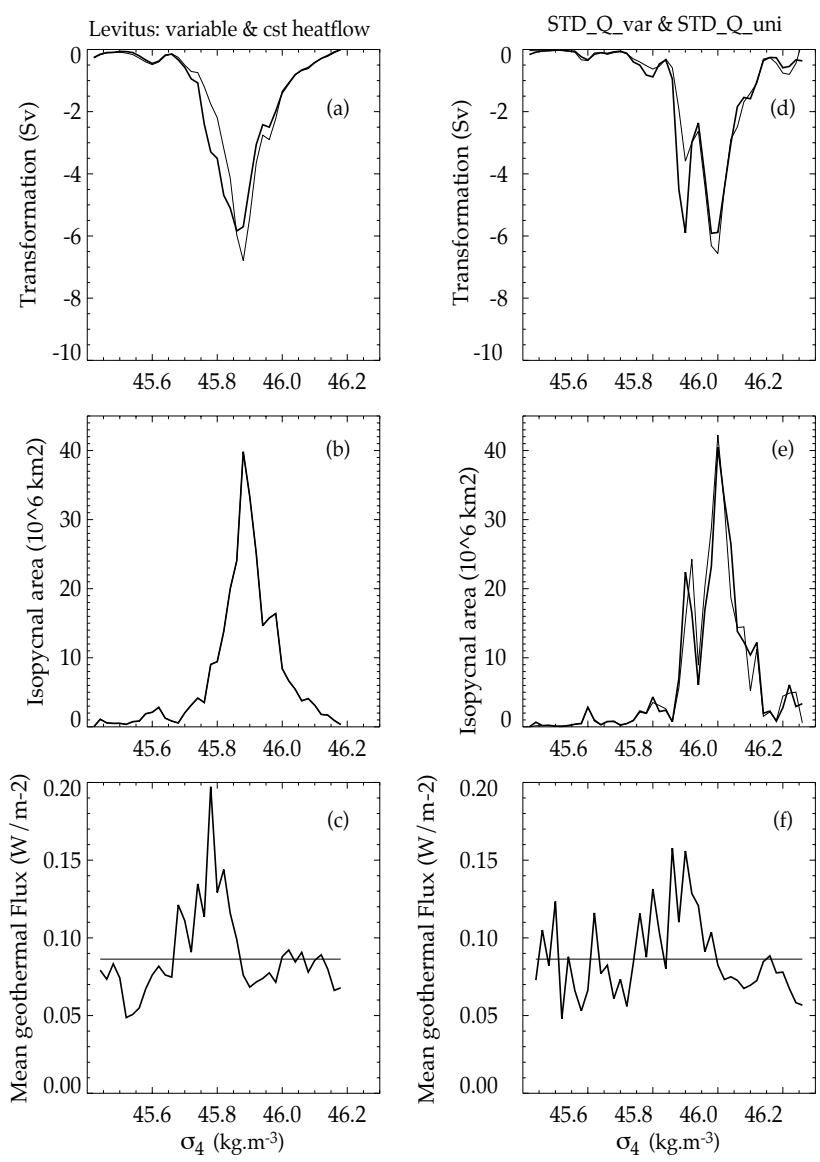

Fig. 5. Density binning in the abyssal ocean. The left hand side shows the result of the density binning method projected onto the thermohaline structure from Levitus. The right hand side refers to numerical experiments STD_Quni and STD_Qvar. (a) and (d): transformation for a spatially variable (bold line) and uniform (solid line) heatflow. (b) and (e): Area spanned by each pair of isopycnals (with a $0.02 \mathrm{~kg} \mathrm{~m}^{-3}$ binning interval). (c) and (f) geothermal heat fluxes distribution among isopycnals. The upper curves can be roughly obtained by multiplying the area by the flux in each density bin (i.e. $(\mathrm{a}) \approx(\mathrm{b}) \times(\mathrm{c})$ and $(\mathrm{d}) \approx(\mathrm{e}) \times(\mathrm{f})$ ).

Not surprisingly, the heat flux curve is flat in the uniform case, whereas the spatially variable heat flux shows a maximum contribution for intermediate densities $(\sigma=45.80)$, and a minimum for higher densities $(\sigma \simeq 46.00)$ : the flux is higher in the NADW depth range and decreases on abyssal plains, where the heavier AABW is found. The transformation induced by the spatially uniform heatflow in Fig. 5a displays a maximum at $\sigma=45.85$ of about $6.5 \mathrm{~Sv}$. In contrast, the spatially variable heatflow (Fig. 5c) injects more heat into the intermediate density classes (lighter than $\sigma=45.85$ ) which tends to shift the transformation towards the left (Fig. 5a), as well as reducing it slightly to $6 \mathrm{~Sv}$. Overall, the difference with a uniform heatflow is fairly small.

Thus, with the current thermohaline structure, this diagnosis reveals that geothermal heating transforms about $6 \mathrm{~Sv}$ across the $\sigma=45.90$ isopycnal, where we should therefore expect the maximum transport. Moreover, we can also expect spatial variations of the heat flux to shift this transport towards lighter isopycnals. Equation (10) shows how the convergence of diffusive fluxes prevents the entirety of this transformation to be converted into circulation $\psi_{c}$. Typically, turbulent mixing reduces such transports by roughly a factor of two in the surface ocean. This ratio cannot be determined within this simple thermodynamic framework, so we now turn to a dynamical model to explore the interplay between these two processes.

\section{Geothermal heating and the abyssal circulation: the dynamic method}

\subsection{The OPA model}

We employ the OPA ocean GCM (Madec et al., 1998; Delecluse and Madec, 1999), in its global configuration ORCA2-LIM (Timmermann et al., 2005). The horizontal mesh is based on a $2^{\circ} \times 2^{\circ}$ Mercator grid (i.e. same zonal and meridional grid spacing) which has been modified poleward of $20^{\circ} \mathrm{N}$ in order to include two numerical inland poles (Murray, 1996). This modification is semi-analytical (Madec and Imbard, 1996) and based on a series of embedded ellipses. It insures that the mesh remains close to isotropy and that the smallest grid cell is along Antarctica. In order to refine the meridional resolution up to $0.5^{\circ}$ at the equator, additional local transformations were applied within the Tropics. There are 31 levels in the vertical, with the highest resolution $(10 \mathrm{~m})$ in the upper $150 \mathrm{~m}$. The bottom topography and the coastlines are derived from the global atlas of Smith and Sandwell (1997). The vertical mixing parameterization scheme is computed by a model based on a turbulent kinetic energy prognostic equation (Blanke and Delecluse, 1993), and there is a diffusive bottom boundary layer parameterization (Beckmann and Doescher, 1997). Vertical mixing asymptotes to a background diffusivity of $0.1 \mathrm{~cm}^{2} \mathrm{~s}^{1}$ in the deep ocean interior. Mixing due to convection was parameterized by locally enhancing the vertical diffusivity in statically unstable situations. Lateral mixing is computed along isopycnal surfaces, supplemented with the Gent and Williams (1990) eddy-induced velocity parameterization (Lazar et al., 1999). The mixing coefficient of the latter depends on the baroclinic instability growth rate (Treguier et al., 1997). The upper boundary of the model is a linear free surface (Roullet and Madec, 2000).

We ran three sets of experiments, described as follows:

- CBW experiments: Preliminary experiments were carried out with a cruder version of the GCM (ORCA2), without a sea ice model. Sea ice cover was prescribed from climatological observations, which tended to produce anomalously cold bottom water (CBW) with very 
Table 1. Summary of the numerical experiments used in this study. The numbers given for $Q_{\text {geo }}$ are its global mean in each experiment.

\begin{tabular}{lllr}
\hline Set & Experiment & $\begin{array}{l}Q_{\text {geo }} \\
\left(\mathrm{mW} \mathrm{m}^{-2}\right)\end{array}$ & $\begin{array}{c}K_{z} \\
\left(\times 10^{-4} \mathrm{~m}^{2} \mathrm{~s}^{-1}\right)\end{array}$ \\
\hline CBW & CBW & Uniform, 0 & 0.1 \\
& CBW_Quni & Uniform, 86.4 & 0.1 \\
\hline \multirow{2}{*}{ STD } & STD & Uniform, 0 & 0.1 \\
& STD_Quni & Uniform, 86.4 & 0.1 \\
& STD_Qvar & Variable, 86.4 & 0.1 \\
\hline \multirow{2}{*}{ MIX } & MIX & Uniform, 0 & 0.1 to 1.2 \\
& MIX_Qvar & Variable, 86.4 & 0.1 to 1.2 \\
\hline
\end{tabular}

little circulation. Imperfect though it is, this configuration turns out to be very close to the limit case of a homogeneously cold abyssal ocean (cf Sect. 4), and is therefore useful in understanding the physics of the response to a uniform geothermal heating of $86.4 \mathrm{~mW} \mathrm{~m}^{-2}$ (experiment CBW_Quni).

- STD experiments: The reference version of ORCA2LIM, as decribed above, was used for 3 experiments. The first one has no geothermal heating (experiment STD). The second one differs only by a uniform geothermal heating of $86.4 \mathrm{~mW} \mathrm{~m}^{-2}$ (experiment STD_Quni). The third has the realistic geothermal heatflow of Fig. 1) with the same global mean (experiment STD_Qvar).

- MIX experiments: Because the vertical diffusivity of the model is quite low compared to most OGCMs, we performed two additional experiments with ORCA2-LIM with enhanced vertical mixing. The model background vertical diffusivity increases from surface to bottom, mimicking the effects of decreased stratification and increased small-scale turbulence near the bottom. (Values range from $1.2 \times 10^{-5} \mathrm{~m}^{2} \mathrm{~s}^{-1}$ in the first $1000 \mathrm{~m}$ to $1.2 \times 10^{-4} \mathrm{~m}^{2} \mathrm{~s}^{-1}$ at $\left.5000 \mathrm{~m}\right)$. Further detail on these experiments can be found in Iudicone et al. (2008c,a). The first experiments, MIX, is identical to STD except for this modified $K_{z}$ profile. Similarly, MIX_Qvar is the counterpart of STD_Qvar with enhanced vertical mixing. The setup is summarized in Table 1.

All experiments were carried out to equilibrium $\left(\left|\partial_{t} T\right| \leq 0.01^{\circ}\right.$ century i.e. $\sim 1500$ years $)$. In all the following, the streamfunction is computed on the zonal mean "effective" velocity; that is, the sum of the Eulerian velocity and the eddy-induced velocity produced by the Gent and Williams (1990) parameterization.
Table 2. Quantification of the geothermally induced transports using 2 different methods. The first row gathers basin-by-basin estimates with the density-binning method of Sect. 4 . The second row gathers corresponding figures derived from $\Psi_{\text {eff }}$ in the CBW experiment.

\begin{tabular}{lrrrr}
\hline Basin & Atlantic & Indian & Pacific & Total \\
\hline Max. Transformation (Sv) & -2.1 & -1.3 & -5.1 & -8.5 \\
GCM Transport (Sv) & -0.5 & -1.0 & -3.5 & -5.0 \\
\hline
\end{tabular}

\subsection{Effect of a uniform geothermal heating}

In Fig. 6 we present the results of the CBW set of experiments. The reference experiment, CBW (Fig. 6a) has a fairly weak thermohaline circulation in the North Atlantic Deep Water (NADW) depth range (1000 to $2500 \mathrm{~m})$, partly because of the low vertical mixing rate $\left(10^{-5} \mathrm{~m}^{2} \mathrm{~s}^{-1}\right)$. The bottom water circulation is almost non-existent, due to anomalous surface fluxes resulting from the absence of a realistic sea-ice model, which filled the last $2000 \mathrm{~m}$ of the model ocean with exceedingly cold water. Together with the low mixing, this strongly inhibits Antarctic Bottom Water (AABW) formation.

Under the influence of a uniform heatflow of $86.4 \mathrm{~mW} \mathrm{~m}^{-2}$, the model reacts by producing a fairly intense circulation cell in the AABW depth range: Fig. $6 \mathrm{~b}$ shows that after 2000 years of integration, the streamfunction difference between experiments CBW and CBW_Quni culminates at $\sim 5 \mathrm{~Sv}$ at a depth of $3500 \mathrm{~m}$ and $35^{\circ} \mathrm{S}$, comparable in magnitude, but weaker than the observational estimates of Orsi et al. (1999).

This transport anomaly is accompanied by a large warming of the abyss, visible in Fig. 6c. The last $3000 \mathrm{~m}$ of the model have warmed by 0.1 to $0.5^{\circ} \mathrm{C}$, a very large change for this relatively uneventful portion of the ocean. The maximum of $0.5^{\circ} \mathrm{C}$ at $50^{\circ} \mathrm{N}$ is located at the bottom of the North Pacific basin. This should not come as a surprise, since we have found in Sect. 3 that it is the location where geothermal heating should be felt most strongly (it is equivalent to a diapycnal mixing of $\sim 3 \times 10^{-4} \mathrm{~m}^{2} \mathrm{~s}-1$ there). In addition, the region exhibits a marked horizontal recirculation in the interior (not shown), allowing bottom water to feel the influence of geothermal heating for a long time. The combined effect of these thermal and kinematic changes is an increase in poleward heat transport by $10 \%$ at $50^{\circ} \mathrm{S}$ (Fig. 12).

The experiments STD and STD_Quni give us complementary information about the adjustment to geothermal heating. Fig $7 b$ shows the circulation in experiment STD. In contrast to $\mathrm{CBW}$, the presence of an interactive sea-ice model leads to a stronger $\mathrm{AABW}$ circulation $(6 \mathrm{~Sv})$ in this simulation, resulting in a more realistic thermal structure (not shown). If geothermal heating is added (experiment STD_Quni), the 

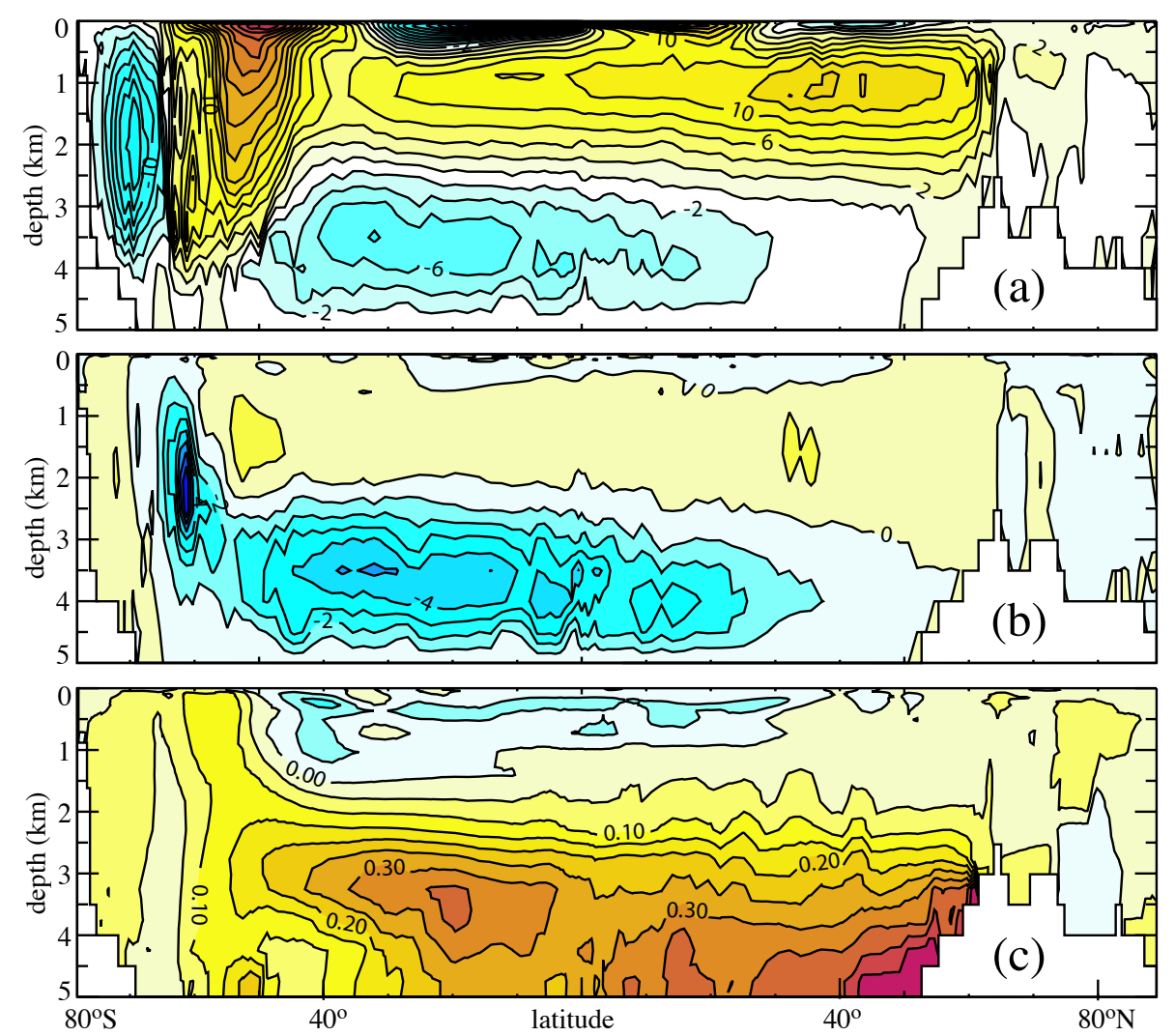

Fig. 6. Outcome of the CBW simulations after 2100 years of integration. (a) Meridional effective overturning streamfunction ( $\Psi_{\text {eff }}$, Sv) in CBW. (b) $\Psi_{\text {eff }}$ difference, CBW_Quni - CBW (Sv). (c) Potential temperature difference (CBW_Quni - CBW) in ${ }^{\circ} \mathrm{C}$. Note the intensification of the bottom water circulation of about $5 \mathrm{~Sv}$ in CBW_Quni, and the zonal mean warming of the bottom $2000 \mathrm{~m}$ of the ocean.

deep circulation again intensifies, as shown in Fig. 8a, however the difference in streamfunction maxima is found less extreme than for CBW_Quni-CBW (3 Sv instead of $5 \mathrm{~Sv}$ ). This is because lateral temperature gradients are larger in this set of experiments, so a lesser increase in circulation is required to evacuate the heat input from the seafloor.

In Table 2 we summarize the results obtained by the two independent methods (density binning and GCM transport in the limit of small vertical mixing) to evaluate the response of the ocean to a uniform heatflow. It is seen that the maximum in transformation is systematically greater than the circulation diagnosed from GCM experiments, confirming that diapycnal mixing partially compensates geothermally-induced advection in the model. The discrepancy proves even larger in the case of strong vertical mixing (not shown). This occurs because the bottom boundary heatflow acts to erode the initial stratification, which diminishes the downward turbulent heat flux $K_{z} \partial_{z} T$. There is thus less heating convergence at depth, thus less need for a cold water source to balance the heat budget, which in steady-state implies a circulation slowdown. Therefore, any finite amount of diapycnal mixing will lead to circulations systematically lower than those diagnosed from the geothermal transformation alone. However, the interplay between the two processes is quite non-linear, as will be seen again in Sect. 5.4. It is also noteworthy that this discrepancy is much larger in the Atlantic basin than in others: this is not surprising, since we have seen in Sect. 3 that it is where the water mass configuration most strongly favors the impact of diapycnal mixing over geothermal heating.

\subsection{Effect of a spatially variable geothermal heat flux}

In Fig. 8c we plot the global streamfunction difference between experiments STD_Qvar and STD_Quni. One can see that the effect of the spatial variations is to reduce the AABW circulation by $\sim 1.5 \mathrm{~Sv}$ (Fig. 8 b). In the temperature field (Fig 9), the effect is to enhance the warming at mid-depth by about 0.02 degrees, and to reduce it near the bottom (by up to $0.1{ }^{\circ} \mathrm{C}$ in the North Pacific). This can be easily understood by considering the horizontally-integrated heatflow at each depth in the "realistic" and "uniform" case (Fig. 10). The dash-dotted line, representing the difference between the two cases, explains this result: with a spatially variable heatflow, the ocean receives more heat at moderate depths (2000 to $3000 \mathrm{~m}$ ) where the flux is at a maximum near mid-ocean ridges. It receives comparatively less 

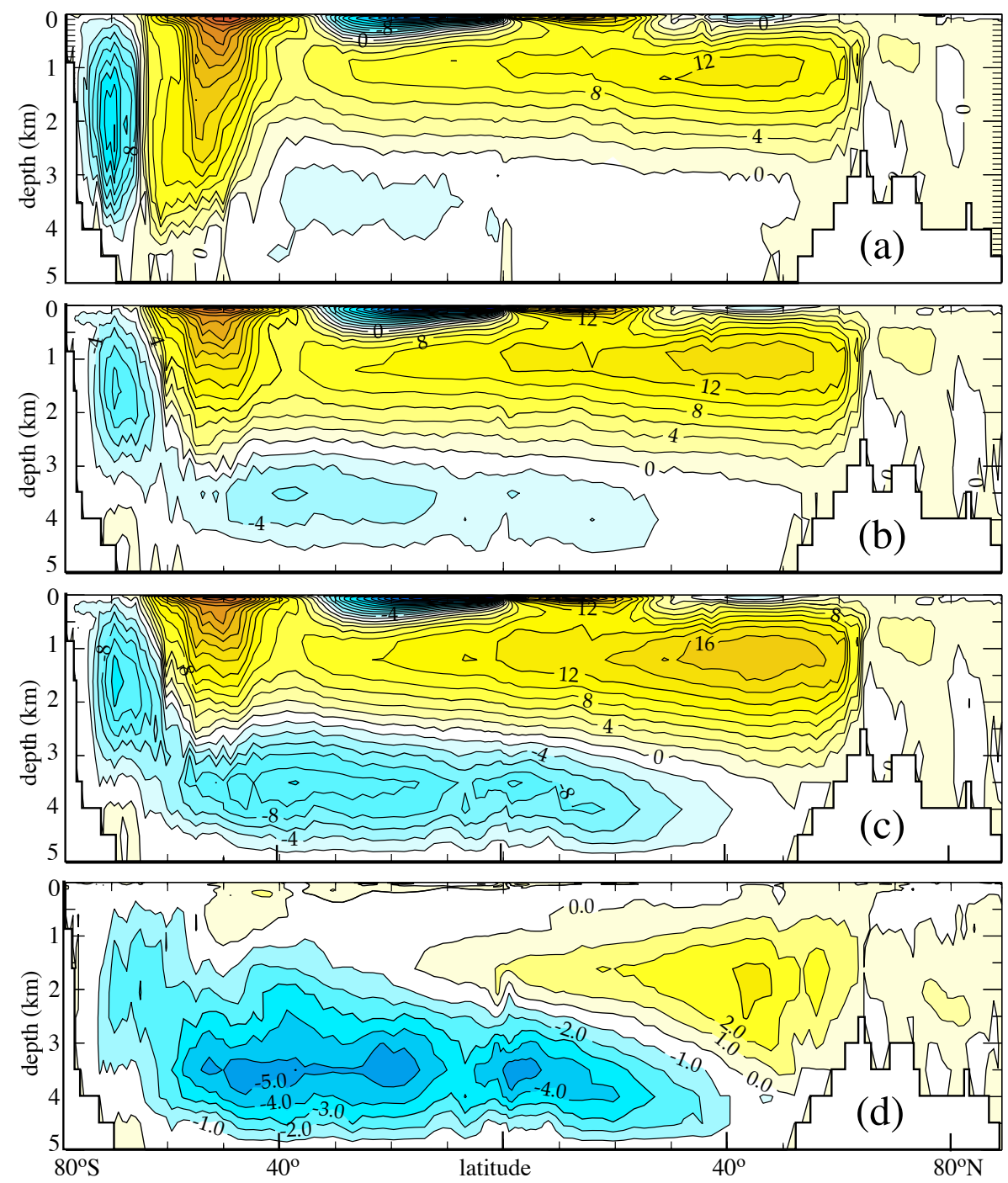

Fig. 7. Global effective meridional streamfunction ( $\Psi_{\text {eff }}, \mathrm{Sv}$ ) for the 3 reference experiments: (a) CBW, (b) STD, (c) MIX and (d) $\Delta \Psi_{\text {eff }}$ : MIX - STD (Sv). Note the large increase in circulation from STD to MIX, particularly for AABW. Note that the contour interval has been decreased from 2 to $0.5 \mathrm{~Sv}$ in (d).

heat below 4000-4500 $\mathrm{m}$, where the realistic heatflow falls under its global average $\left(\sim 50 \mathrm{~mW} \mathrm{~m}^{-2}\right.$ vs $\left.86.4 \mathrm{~mW} \mathrm{~m}^{-2}\right)$. Because heat is now deposited at shallower levels, the temperature field follows suit. The consequence is that maintaining the abyssal temperature heat balance in STD_Qvar can be achieved with a weaker AABW circulation than in STD_Quni, as observed in Fig. 8b. The net result is a sizable slowdown of the circulation and a modest (second order) temperature change compared to the case of a uniform heatflow.

\subsection{Effect of vertical mixing}

Some of the preceding results are arguably a consequence of the low vertical mixing rate used in the model $\left(K_{z}\right)$, which does not take into account the increase in near-bottom mix- ing rate shown by observational studies (Toole et al., 1994; Polzin et al., 1997). We wish to know whether our results stand in the case of a more realistic $K_{z}$ profile, which would modify the deep thermohaline structure upon which geothermal heating is acting. Experiment MIX has a vertical mixing rate increasing from $1.2 \times 10^{-5} \mathrm{~m}^{2} \mathrm{~s}^{-1}$ in the thermocline to $1.2 \times 10^{-4} \mathrm{~m}^{2} \mathrm{~s}^{-1}$ at $5000 \mathrm{~m}$. Based on the work of Bryan (1987) and followers, we expect that this increase will enhance the intensity of the meridional overturning circulation (MOC) and this is indeed what is observed (Fig. 7b, c, and d): between experiments STD and MIX, the NADW circulation increases from 14 to $16 \mathrm{~Sv}$, the AABW circulation from 6 to $12 \mathrm{~Sv}$. This is a more reasonable estimate owing to the watermass analyses of Orsi et al. (1999) and Ganachaud and Wunsch (2000). The corollary effect is that horizontal surface 

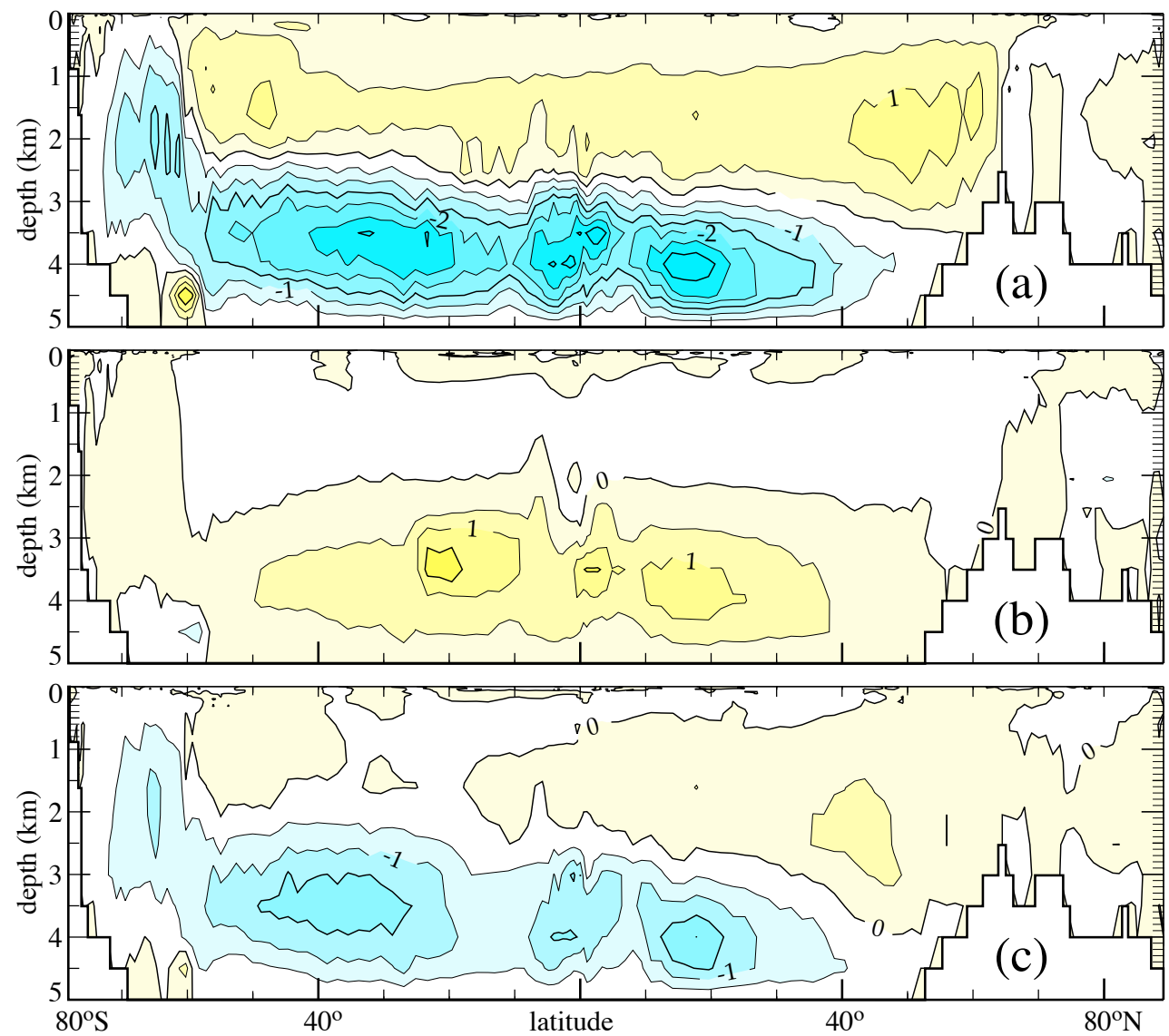

Fig. 8. Global effective meridional streamfunction difference ( $\Delta \Psi_{\text {eff }}$, Sv) for 3 doublets of experiments: (a) STD_Quni - STD ; (b) STD_Qvar - STD_Quni, (c) MIX_Qvar - MIX.

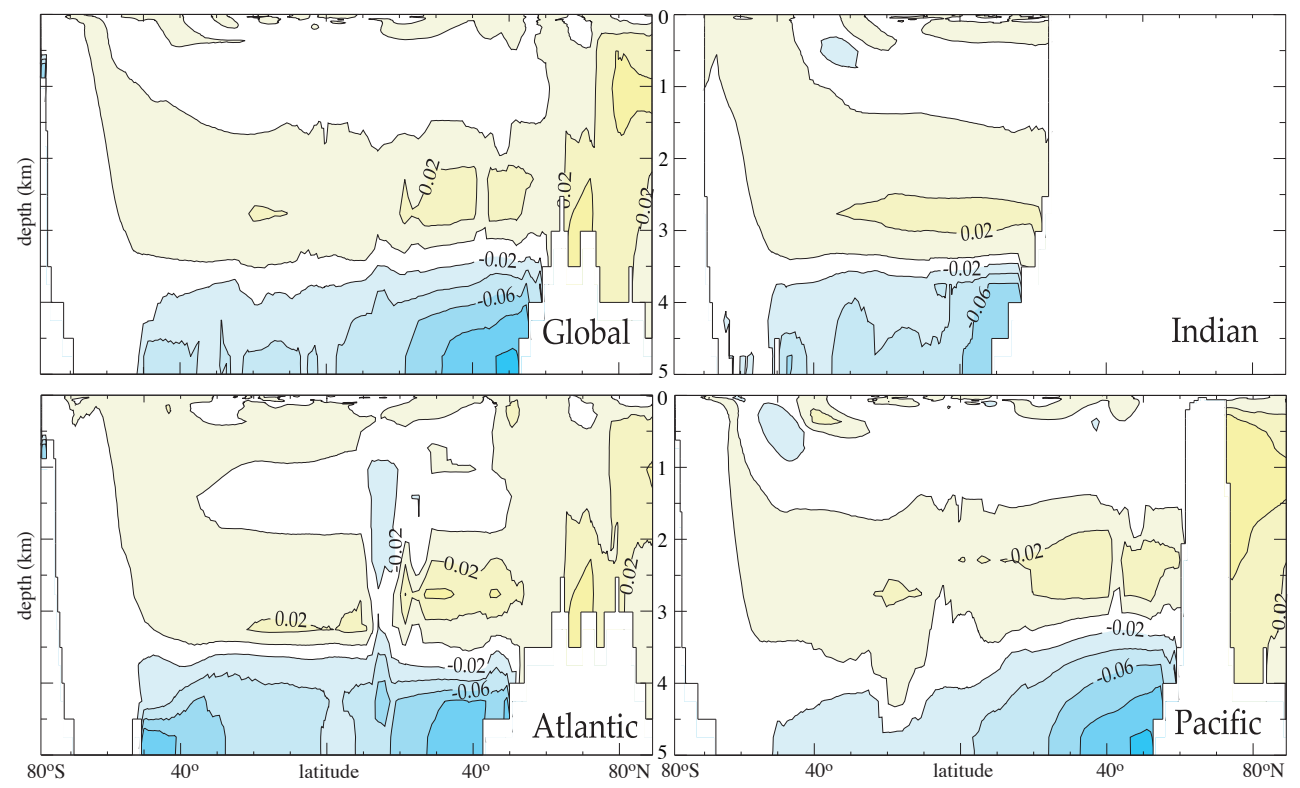

Fig. 9. Potential temperature difference between STD_Qvar and STD_Quni at equilibrium $\left({ }^{\circ} \mathrm{C}\right)$. 
temperature gradients (primarily meridional, on very large scales) are mapped by vertical diffusion onto the near bottom temperature field, which thus becomes less homogenous than in the limit of no vertical mixing (experiments CBW).

Since we have already seen the effect of a realistic geothermal heating on the model in the previous section, we ran only one experiment with non-zero geothermal flow, one where it is spatially varying (MIX_Qvar). The difference MIX_QvarMIX is presented in Fig. 8. The general bottom circulation is otherwise very similar. Figure 8 shows a maximum of $1.5 \mathrm{~Sv}$ for the geothermal circulation, which is about $10 \%$ of the total AABW circulation in MIX_Qvar, and almost 50\% lower than in STD_Qvar. This occurs because enhanced vertical mixing generates stronger lateral gradients in temperature, which means that compensating for geothermal heat input can be achieved with a slower circulation than before. Thus, we find that for a strong abyssal mixing rate, the dynamical effect of a realistic heatflow is to enhance the AABW circulation by $1.5 \mathrm{~Sv}$, weaker than in STD_Qvar. The thermodynamic effect is also reduced: a large-scale warming of abyssal oceans by about $0.15^{\circ} \mathrm{C}$ peaking around $0.3^{\circ} \mathrm{C}$ in the bottom North Pacific (not shown). This is a consequence of the reduction in deep stratification induced by geothermal heating, which diminishes the downward turbulent heat flux below the thermocline. In summary, the interaction of geothermal heating and diapycnal mixing is quite non-linear. As explained above, this is because both forcings affect the deep temperature gradients, which conditions both the strength of the downward diffusive heat flux and the intensity of the geothermal circulation.

One way to see this is to take the mid-ocean temperature (say at $2000 \mathrm{~m}$ ) to be fixed by the source of North Atlantic and Circumpolar Deep Water (determined mostly by atmospheric forcing an sea-ice physics). Re-arranging Eq. (4), then:

$$
\left|\frac{\partial T}{\partial z}\right|=\left|\frac{1}{K_{z}}\right|\left|\frac{Q_{\mathrm{geo}}}{\rho_{\circ} C_{p}}\right|
$$

So the vertical gradient of temperature and hence the additional deep temperature increase due to geothermal heating is seen to be inversely proportional to the "effective" mixing coefficient (i.e. the combined effect of mixing and advection). Turning up the diapycnal mixing rate of the model thus mixes away the heat added by geothermal heating.

\subsection{The view in density space}

One can partially bypass this nonlinearity by looking at the circulation in density space, that is, transform the vertical coordinate by $\sigma_{4}$. This transformation reveals the details of the deep circulation in a different light (Fig 11): geothermal heating always intensifies the AABW cell by $\sim 2 \mathrm{~Sv}$, while slightly shifting the overturning maximum towards lighter density classes. Because both $Q_{\text {geo }}$ and $K_{z}$ affect the ocean's

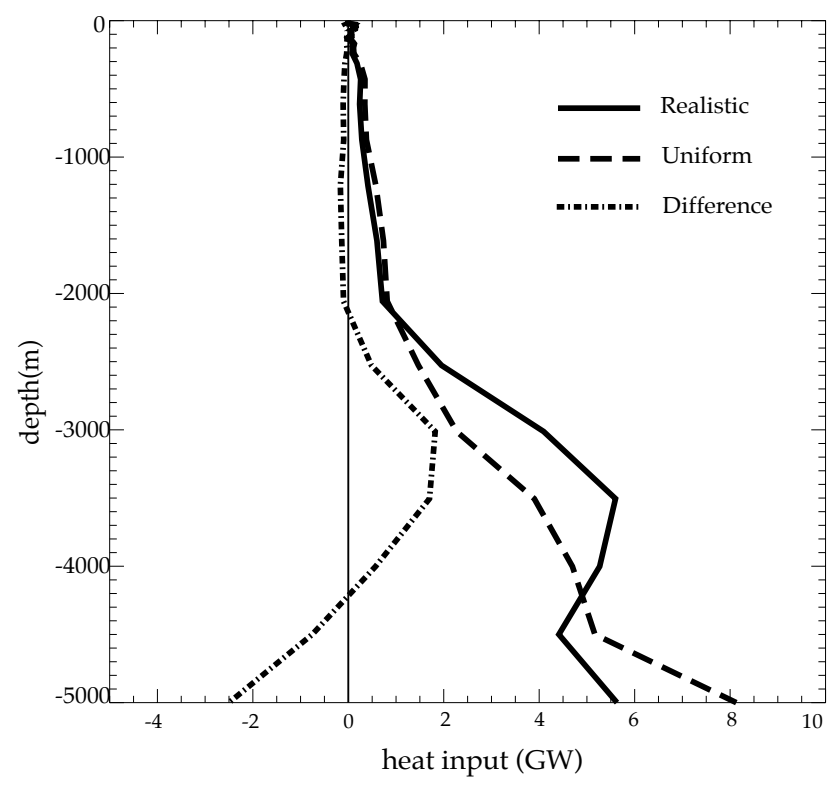

Fig. 10. Vertical distribution of geothermal heating weighted by the seafloor area at each depth. Solid line: realistic spatial structure (cf Fig. 1). Dashed line: uniform heat flow $\left(86.4 \mathrm{~mW} \mathrm{~m}^{-2}\right)$. Dashdotted: "realistic" minus "uniform".

density structure, subtracting streamfunctions in density coordinates proves meaningless. One can however use this representation to track the maximum $\mathrm{AABW}$ overturning at each latitude (not shown), which displays up to a $5 \mathrm{~Sv}$ increase between CBW and CBW_Quni, a 3.5 Sv increase between STD and STD_Quni, and 2.5 Sv in the case of a spatially variable heat flux (STD_Qvar-STD). Remarkably, this increase is independent of the value of $K_{z}$, as it is identical for MIX_Qvar-MIX.

Table 3 summarizes the model's response in the pairs of experiments that have been discussed here.

\subsection{Effect on heat transport}

In Fig. 12 we plot northward heat transport in our experiments (note that curves showing the difference between two experiments have been magnified by 10 to plot on the same graph). Geothermal heating enhances heat transport in the Southern Hemisphere (and very modestly so in the Northern Hemisphere) because the additional heat input of $0.03 \mathrm{PW}$ must be evacuated from the abyss, which is achieved by warming $\mathrm{AABW}$ and enhancing its circulation.

It is remarkable that experiments with such different thermal structures and circulations as CBW and MIX end up displaying very similar changes in heat transport $(\sim 10 \%$ increase in poleward heat transport in both cases). Whether the flux is uniform or realistic seems to induce almost no difference in transport at all (STD experiments, not shown). The changes between CBW and MIX are, however, not identical in the Southern Ocean, where most of the heat is released to 

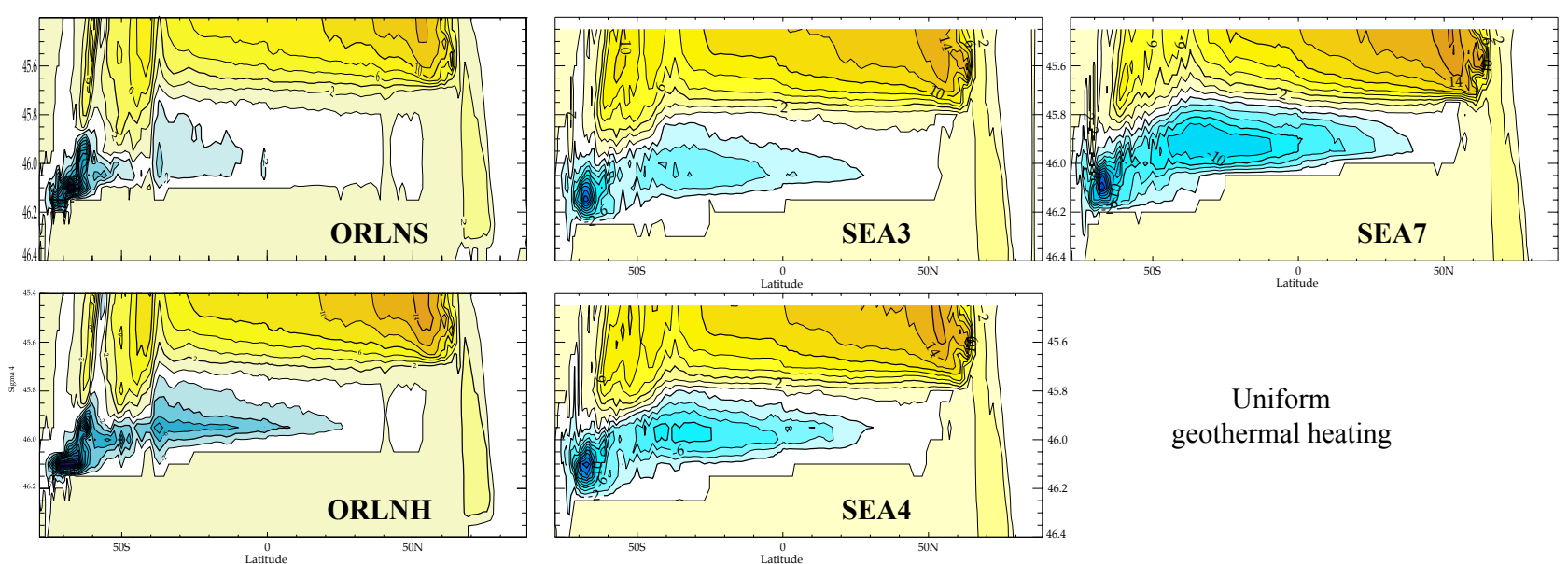

Uniform

geothermal heating

Spatially varying geothermal heating

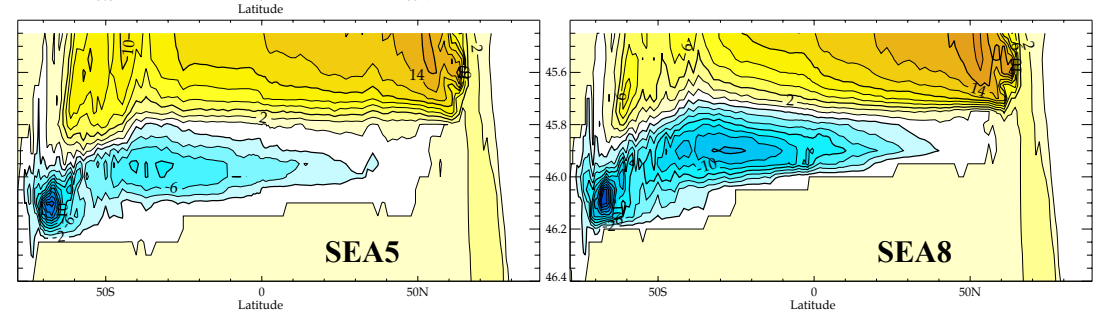

Fig. 11. Density-binned meridional overturning stream functions for all experiments. (Contour interval=2 Sv) As in Fig. 6 or Fig. 7 , with the vertical axis $z$ replaced by $\sigma_{4}$. The first row gathers control experiments with zero geothermal heating; the second has uniform geothermal heating; the third has realistic spatial variations. Deep mixing increases from left to right.

Table 3. Maximum density-interploated streamfunction $\Psi_{\sigma}$ and zonally-averaged peak abyssal temperature difference $\langle\Delta T\rangle$ in selected numerical experiments.

\begin{tabular}{lcccc}
\hline Experiment Pair & CBW_Quni-CBW & STD_Quni - STD & STD_Qvar - STD & MIX_Qvar - MIX \\
\hline$\Psi_{\sigma}(\mathrm{Sv})$ & 5 & 3.5 & 2.5 & 2 \\
$\langle\Delta T\rangle\left({ }^{\circ} \mathrm{C}\right)$ & 0.5 & 0.5 & 0.45 & 0.15 \\
\hline
\end{tabular}

the atmosphere. In CBW, where the background circulation is so weak and stratification so strong, geothermal heating produces a maximum transport anomaly near $50^{\circ} \mathrm{S}$, peaking at $-0.07 \mathrm{PW}$ (about twice the geothermal forcing). In the MIX experiments, the model reacts much more moderately to the addition of the forcing, peaking at $-0.04 \mathrm{PW}$ : geothermal heat flux is mixed more effectively into different water masses and therefore is more evenly distributed across each latitude band, leading to weaker lateral temperature gradients, hence a weaker heat transport.

\section{Discussion}

We have explored the dynamical role of geothermal heating in the abyssal circulation using three different and largely independent approaches. These led us to the following conclusions:
- Geothermal heating can force a circulation in the abyss, comparable to the Stommel-Arons circulation. This forcing enhances the Antarctic Bottom Water overturning cell by about 1.5 to $5 \mathrm{~Sv}$ in our GCM experiments, consistent with a density-binning diagnosis. The low end of this range is smaller than the uncertainty of the current estimates of $\mathrm{AABW}$ circulation, therefore the dynamical effect can overall be considered weak: it is not a first order feature, but not a negligible one either.

- On the other hand, the thermodynamic response is considerable, with bottom waters warming by about $0.3^{\circ} \mathrm{C}$, with a maximum of $0.5^{\circ} \mathrm{C}$ in the North Pacific bottom waters (slightly smaller in the strong mixing case), in agreement with Adcroft et al. (2001). This is an enormous contribution to the heat budget of the deep ocean, one that cannot be neglected. 


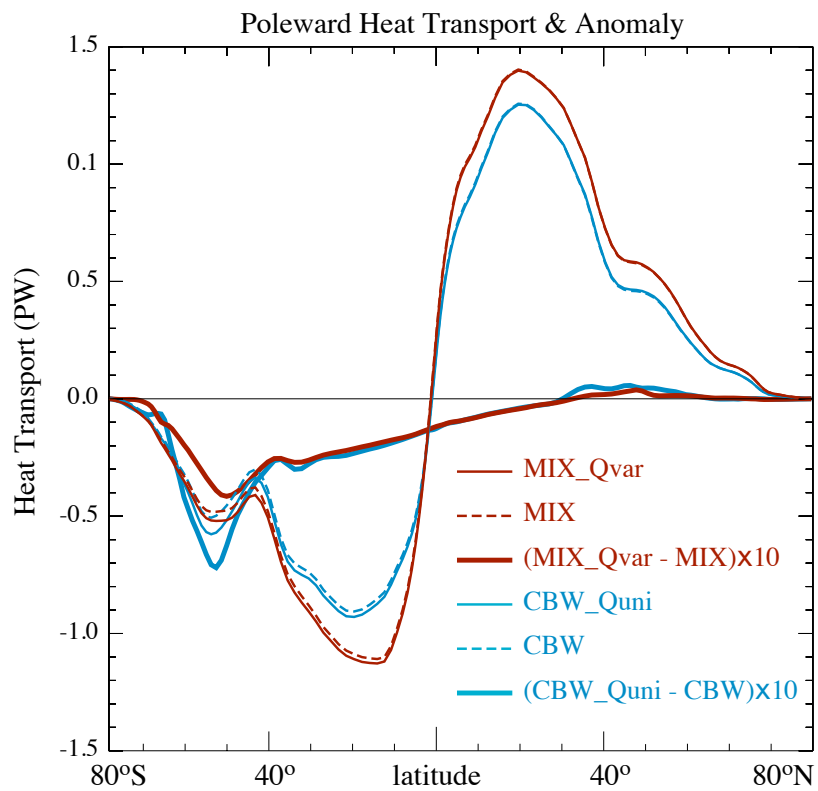

Fig. 12. Global meridional heat transport. Only two extreme cases are presented, from the $\mathrm{CBW}$ and MIX families of experiments. Note that the differences (CBW_Quni - CBW) and (MIX_Qvar MIX) have been multiplied by 10: the additional heat transport due to geothermal heating peaks at about $10 \%$ of the total around $50^{\circ} \mathrm{S}$.

- geothermal heat flux is formally analogous to air-sea fluxes, and likewise, it induces a transformation of water masses (AABW in this case). However, an essential distinction is to be made: geothermal heating does not form any water mass stricto sensu, and rather, its systematically positive sign leads to "consume" the densest water masses.

- In that sense, it is directly analogous to diapycnal mixing, both qualitatively and quantitatively. It has a similar effect on bottom water, eroding extrema of the global T$\mathrm{S}$ diagram and depositing a comparable amount of heat in the abyss. On a global scale, it is in fact equivalent to a diapycnal mixing coefficient of $\sim 1.2 \times 10^{-4} \mathrm{~m}^{2} \mathrm{~s}^{-1}$ at $3500 \mathrm{~m}$, i.e. the canonical value of (Munk, 1966).

- The density-binning method enables the quantification of the water-mass transformation induced by geothermal heat flux. Best estimates of the spatial variability of the flux and of the deep thermohaline structure yield a transformation maximum of $\sim 6 \mathrm{~Sv}$ at $\sigma_{4}=45.90$ (in the AABW range). This rate can be thought of as the expected circulation in the absence of mixing; in the presence of mixing it will be partially compensated by the divergence of diffusive fluxes. There is a fundamental difference, however: diapycnal fluxes act throughout the water column, below the main thermocline. While comparable in magnitude in the deepest layers, geother- mal heating acts only on the densest water masses, with very little impact higher in the water column.

- Indeed, any amount of diapycnal mixing will lead to circulations systematically lower than diagnosed from geothermal transformation alone. The interplay between the two processes is quite non-linear, with geothermal heating reducing the deep thermal stratification upon which diffusion is acting, while vertical mixing alters the lateral temperature gradients that support a geothermal circulation. In $z$-coordinate, this results in geothermal circulations that are highly sensitive to $K_{z}$; this dependence is considerably reduced in $\sigma$ coordinates, from which we derive a conservative estimate of a $15 \%$ enhancement of the deep circulation due to geothermal heating.

- The spatial structure of the flux yields, consistently with its vertical distribution, a weaker response at great depth (abyssal plains) than in the uniform case. The relative cooling reaches up to $0.06-0.08^{\circ} \mathrm{C}$ there, with an opposite response at the typical depth of mid-ocean ridges $(2500 \mathrm{~m})$, which warm up by about $0.02^{\circ} \mathrm{C}$. The mean overturning circulation is then reduced by $\sim 0.5$ to $1 \mathrm{~Sv}$. The difference is independent of vertical mixing.

- A remarkable finding is that the increase in ocean heat transport was nearly constant across experiments, despite the broad range of thermal and circulation changes they encompass. The presence of a geothermal heatflow, whether spatially variable or not, means that the ocean must evacuate an additional $0.03 \mathrm{PW}$, which it does in all cases by enhancing poleward heat transport in the Southern Hemisphere, by about $10 \%$ near $50^{\circ} \mathrm{S}$.

Our numerical results are broadly consistent with Adcroft et al. (2001) and Scott et al. (2001), in that they confirm geothermal circulation to be inversely proportional to near-bottom temperature gradients. Also, both studies show a strong thermodynamic response contrasting with a fairly weak dynamical response. This is somewhat surprising, since in this mode of heating at low-geopotential heights, the ocean was expected to behave like a heat engine (Huang, 1999; Marchal, 2007). Yet we find that most of the heat input goes into raising the potential energy of the ocean; very little of it is actually converted into kinetic energy. This confirms that heat fluxes are rather inefficient sources of motion in the ocean, compared to momentum fluxes due to winds or tides (Wunsch and Ferrari, 2004). We note, however, that some portion of this potential energy must also serve to achieve mixing, as pointed out by Huang (1999). However, no significant changes in convective instability were noticed here. The effect of geothermal heat flux is largely confined to the heat balance; like diapycnal heat fluxes, it is only a driving force of the circulation via the heat equation. As clearly demonstrated by Scott et al. (2001), this is because advection is the most efficient way of removing heat from the abyss. 
In this work as in most studies, we have fixed the mixing coefficient $K_{z}$, disregarding the energetic requirements of the mixing process. If, as suggested by Huang (1999), we were to fix the "energy" available for mixing, the turbulent heat flux would then be constrained by the mechanical input from winds and tides (Wunsch and Ferrari, 2004), and geothermal circulation should be presumably less sensitive to the mixing rate. This will be left for future work.

The case is hereby made that geothermal heating is an important actor of abyssal dynamics. We recommend its inclusion in every model dealing with the long-term ocean circulation, for it substantially alters bottom water mass characteristics and generates a non-negligible circulation in the present-day climate. Further, recent results by Dutay et al. (2008) confirm its importance in correctly simulating tracer distributions in the deep ocean. The case corresponding to MIX_Qvar appears to be the most relevant to most users, but it would be most interesting to prescribe it in conjunction with state-of-the-art parameterizations of diapycnal mixing. Data for the spatially variable heatflux (Fig. 1) are available upon request.

A logical consequence of this work is the prediction of a larger geothermal effect in a world of weaker diapycnal mixing. This may plausibly have been the case during quaternary ice ages exemplified by the Last Glacial Maximum (LGM), because of strong haline stratification of the abyssal ocean (Adkins et al., 2002). In such a case, geothermal heating could have been the driving force preventing stagnation of the abyssal ocean in the face of strong stratification, as originally postulated by Worthington (1968). While its steady nature does not make it an ideal candidate for triggering climate change over millenial timescales, there is the intriguing possibility that it convectively destabilized the water column under sea-ice cover at some times in the past, thus modifying, for example, the northern North Atlantic ocean circulation during Ice Ages, as conjectured by Weyl (1968). A recent study by Adkins et al. (2005) advances related ideas for the Southern Ocean, which should be further investigated.

Acknowledgements. The authors acknowledge funding by the CNRS and the Ecole Normale Supérieure, and are indebted to Jess Adkins and Michael Hutnak for useful comments. Most of the results presented in this paper were obtained during JEG's "stage de DEA" at LOCEAN in 2001, for which Marina Levy, Christophe Menkes, Sebastien Masson and Mathieu Langaigne are warmly thanked.

Edited by: T. McDougall

\section{References}

Adcroft, A., Scott, J. R., and Marotzke, J.: Impact of geothermal heating on the global ocean circulation, Geophys. Res. Lett., 29, 1735-1738, 2001.

Adkins, J., McIntyre, K., and Schrag, D. P.: The Salinity, Temperature, and $\delta^{18} \mathrm{O}$ of the Glacial Deep Ocean, Science, 298, 17691773, 2002.

Adkins, J., Ingersoll, A., and Pasquero, C.: Rapid climate change and conditional instability of the glacial deep ocean from the thermobaric effect and geothermal heating, Quaternary Sci. Rev., 24, 581-594, 2005.

Arhan, M., Mercier, H., Bourles, B., and Gouriou, Y.: Hydrographic sections across the Atlantic at 7 degrees $30 \mathrm{~N}$ and 4 degrees $30 \mathrm{~S}$, Deep-Sea Res. Pt. I, 45, 829-872, 1998.

Beckmann, A. and Doescher, R.: A method for improved representation of dense water spreading over topography in geopotentialcoordinate models, J. Phys. Oceanogr., 27, 581-591, 1997.

Blanke, B. and Delecluse, P.: Variability of the tropical Atlantic Ocean simulated by a general circulation model with two different mixed-layer physics, J. Phys. Oceanogr., 23, 1363-1388, 1993.

Bryan, K.: Parameter sensitivity of primitive equation ocean general circulation, J. Phys. Oceanogr., 17, 970-985, 1987.

Delecluse, P. and Madec, G.: Ocean modelling and the role of the ocean in the climate system, in: Modeling the Earth's Climate and its Variability, Les Houches, Session LXVII 1997, edited by: Holland, W. R., Joussaume, S., and David, F., Elsevier Science, 237-313, 1999.

Dutay, J., Emile-Geay, J., Iudicone, D., Jean-Baptiste, P., Madec, G., and Carouge, C.: Helium Isotopic constraints on simulated ocean circulations. Implications for abyssal theories, Environ. Fluid Mech., submitted, 2008.

Ganachaud, A. and Wunsch, C.: Improved estimates of global ocean circulation, heat transport and mixing from hydrographic data, Nature, 408, 453-457, 2000.

Gent, P. and Williams, J. M.: Isopycnal mixing in ocean circulation models, J. Phys. Oceanogr., 20, 105-155, 1990.

Gregg, M. C.: Scaling turbulent dissipation in the thermocline, J. Geophys. Res.-Oceans, 94, 9686-9698, 1989.

Harris, R. N. and Chapman, D. S.: Deep-seated oceanic heat flow, heat deficits and hydrothermal circulation, in: Hydrogeology of the oceanic lithosphere, edited by: Davis, E. and Elderfield, H., Cambridge University Press, Cambridge, UK, 311-336, 2004.

Huang, R.: Mixing and energetics of the thermohaline circulation, J. Phys. Oceanogr., 29, 727-746, 1999.

Hutnak, M. and Fisher, A. T.: Influence of sedimentation, local and regional hydrothermal circulation, and thermal rebound on measurements of seafloor heat flux, J. Geophys. Res., 112, B12101, doi:10.1029/2007JB005022, 2007.

Iudicone, D., Madec, G., Blanke, B., and Speich, S.: The role of Southern Ocean surface forcings and mixing in the global conveyor, J. Phys. Oceanogr., 38, 1377-1400, 2008a.

Iudicone, D., Madec, G., and McDougall, T.: Watermass transformations in a neutral density framework and the key role of light penetration, J. Phys. Oceanogr., 38, 1357-1376, 2008 b.

Iudicone, D., Speich, S., Madec, G., and Blanke, B.: The global conveyor belt from a Southern Ocean perspective, J. Phys. Oceanogr., 38, 1401-1425, $2008 \mathrm{c}$. 
Jackett, D. R. and McDougall, T. J.: Minimal adjustment of hydrographic data to achieve static stability, J. Atmos. Ocean. Tech., 12, 381-389, 1995.

Jaupart, C., Labrosse, S., and Marechal, J.-C.: Temperatures, heat and energy in the mantle of the Earth, in: Treatise on Geophysics, edited by: Schubert, G. and Bercovici, D., Elsevier, 253-303, 2007.

Kunze, E. and Sanford, T.: Abyssal Mixing: Where It Is Not, J. Phys. Oceanogr., 26, 2286-2296, 1996.

Large, W. and Nurser, A. J. G.: Ocean surface water mass transformation, in: Ocean Circulation and Climate: Observing and Modelling the Global Ocean, edited by: Siedler, G., Church, J., and Gould, J., vol. 77 of International Geophysics Series, Academic Press, 317-336, 2001.

Lazar, A., Madec, G., and Delecluse, P.: The Deep Interior Downwelling, the Veronis Effect and Mesoscale Tracer Transport Parameterizations in an OGCM, J. Phys. Oceanogr., 29, 29452961, 1999.

Ledwell, J., Watson, A., and Law, C.: Mixing of a tracer across the pycnocline, J. Geophys.Res. Oceans, 103, 21 499-21 529, 1998.

Levitus, S.: Climatological atlas of the world ocean, Tech. rep., NOAA, Rockville, Md., 1998.

Madec, G. and Imbard, M.: A global ocean mesh to overcome the North Pole singularity, Clim. Dynam., 12, 381-388, 1996.

Madec, G., P.Delecluse, Imbard, M., and Levy, C.: OPA Version 8.1 Ocean General Circulation Model Reference Manual, Note 11, LODYC/IPSL, Paris, France, 1998.

Marchal, O.: Particle transport in horizontal convection: Implications for the "Sandström theorem", Tellus A, 59, 141-154, 2007.

Marshall, J., Jamous, D., and Nilson, J.: Reconciling "thermodynamic" and "dynamic" methods of computation of water mass transformation rates, Deep-Sea Res., 46, 545-572, 1998.

Müller, R., Roest, W., Royer, J.-Y., Gahagan, L., and Sclater, J.: Digital isochrons of the ocean floor, J. Geophys. Res., 102, 32113214, 1997.

Munk, W.: Abyssal recipes, Deep-Sea Res., 13, 707-730, 1966.

Munk, W. and Wunsch, C.: Abyssal recipes II : Energetics of tidal and wind mixing, Deep-Sea Res., 45, 1977-2010, 1998.

Murray, R.: Explicit generation of orthogonal grids for ocean models, J. Comput. Phys., 126, 251-273, 1996.

Nurser, A. G., Marsh, R., and Williams, R.: Diagnosing water mass formation from air-sea fluxes and surface mixing, J. Phys. Oceanogr., 29, 1468-1483, 1999.

Orsi, A., Johnson, G., and Bullister, J.: Circulation, mixing, and production of Antarctic Bottom Water, Prog. Oceanog., 43, 55109, 1999.

Pollack, H., Hurter, S., and Johnson, J.: Heat flow from the Earth's interior: analysis of the global dataset, Rev. Geophys., 31, 276280, 1993.

Polzin, K., Toole, J., Ledwell, J., and Schmitt, W.: Spatial variability of turbulent mixing in the abyssal ocean, Science, 276, 93-96, 1997.

Roullet, G. and Madec, G.: Salt conservation, free surface and varying levels: a new formulation for ocean general circulation models, J. Geophys. Res.-Oceans, 105, 927-942, 2000.

Scott, J., Marotzke, J., and Adcroft, A.: Geothermal heating and its influence on the meridional overturning circulation, J. Geophys. Res., 106, 1-14, 2001.
Send, U. and Marshall, J.: Integral effects of deep convection, J. Phys. Oceanogr., 25, 855-872, 1995.

Smith, W. H. F. and Sandwell, D. T.: Global sea floor topography from satellite altimetry and ship depth sounding, Science, 277, 1956-1962, 1997.

Speer, K., Eguilyardi, G., and Madec, G.: Southern Ocean transformation with or without eddy mass fluxes, Tellus A, 52, 554-565, 2000.

Speer, K. and Tziperman, E.: Rates of water mass formation in the North Atlantic ocean, J. Phys. Oceanogr., 22, 93-104, 1992.

Stein, C. A. and Stein, S.: A model for the global variation in oceanic depth and heat flow with lithospheric age, Nature, 359, 123-129, 1992.

Stein, C. A. and Stein, S.: Constraints on hydrothermal heat flux through the oceanic lithosphere from global heat flow, J. Geophys. Res.-Oceans, 99, 3081-3095, 1994.

Stommel, H. and Arons, A. B.: On the abyssal circulation of the world ocean-II. An idealized model of circulation pattern and amplitude in oceanic basins, Deep-Sea Res., 6, 217-233, 1960.

Stommel, H., Arons, A., and Falle, A.: Some examples of stationary planetary flow patterns in bounded basins, Tellus, 10, 179-187, 1958.

Timmermann, R., Goosse, H., Madec, G., Fichefet, T., Ethé, C., and Dulière, V.: On the representation of high latitude processes in ORCA-LIM global coupled sea-ice-ocean model, Ocean Model., 8, 175-201, 2005.

Toggweiler, J. and Samuels, B.: Effect of Drake passage on the global thermohaline circulation, Deep Sea Res. Pt. I, 42, 477500, 1995.

Toggweiler, J. and Samuels, B.: On the ocean's large-scale circulation near the limit of no vertical mixing, J. Phys. Oceanogr., 28, 1832-1852, 1998.

Toole, J., Polzin, K., and Schmitt, R.: Estimates of diapycnal mixing in the abyssal ocean, Science, 264, 1120-1123, 1994.

Treguier, A., Held, I., and Larichev, V.: Parameterization of Quasigeostrophic Eddies in Primitive Equation Ocean Models, J. Phys. Oceanogr., 27, 567-580, 1997.

Visbeck, M.: Power of pull, Nature, 447, p. 383, 2007.

Walin, G.: On the relation between sea-surface heat flow and thermal circulation in the ocean, Tellus, 34, 187-195, 1982.

Warren, B.: Deep circulation of the world ocean, in: Evolution of Physical Oceanography, edited by: Warren, B. and Wunsch, C., MIT Press, Cambridge, Mass., 6-41, 1981.

Webb, D. J. and Suginohara, N.: Vertical mixing in the ocean, Nature, 409, p. 37, 2001.

Weyl, P. K.: The Role of the Oceans in Climatic Change: A Theory of the Ice Ages, Meteor. Mon., 8, 37-62, 1968.

Whitworth, T., Warren, B., Nowlin, W., Rutz, S., Pillsbury, R., and Moore, M.: On the deep western-boundary current in the Southwest Pacific Basin, Prog. Oceanogr., 43, 1-54, 1999.

Worthington, L.: Genesis and Evolution of Water Masses, Meteor. Mon., 8, 63-67, 1968.

Wunsch, C. and Ferrari, R.: Vertical Mixing, Energy, and the General Circulation of the Oceans, Annu. Rev. Fluid Mech., 36, 281314,2004 